\title{
Diagnosis, clinical course, and 1-year outcome in patients hospitalized for heart failure with preserved ejection fraction (from the Polish Cohort of the European Society of Cardiology Heart Failure Long-Term Registry)
}

\author{
Agnieszka Kapłon-Cieślicka MD, PhD, ${ }^{\mathrm{a}}$ Agata Tymińska MD, ${ }^{\mathrm{a}}$ Michał Peller MD, ${ }^{\mathrm{a}}$ \\ Paweł Balsam MD, PhD, ${ }^{a}$ Krzysztof Ozierański MD, ${ }^{a}$ Michalina Galas MD, ${ }^{a}$ Michał \\ Marchel MD, PhD, ${ }^{a}$ Maria G. Crespo-Leiro MD, PhD, ${ }^{\mathrm{b}}$ Aldo Pietro Maggioni MD, \\ $\mathrm{PhD},{ }^{\mathrm{c}}$ Jarosław Drożdż MD, PhD,${ }^{\mathrm{d}}$ Krzysztof J. Filipiak MD, PhD, ${ }^{\mathrm{a}}$ Grzegorz Opolski \\ $\mathrm{MD}, \mathrm{PhD}^{\mathrm{a}}$
}

${ }^{a}$ First Chair and Department of Cardiology, Medical University of Warsaw, Warsaw, Poland; ${ }^{b}$ Complexo Hospitalario Universitario A Coruña (CHUAC), La Coruña, Spain; ${ }^{c}$ Centro Studi ANMCO (Associazione Nazionale Medici Cardiologi Ospedalieri), Florence, Italy; ${ }^{d}$ Department of Cardiology, First Chair of Cardiology and Cardiac Surgery, Medical University of Łódź, Łódź, Poland

Compared with heart failure (HF) with reduced ejection fraction (HF-REF), the diagnosis of HF with preserved EF (HF-PEF) is more challenging. The aim of the study was to assess the prevalence of HF-PEF among patients hospitalized for HF, to evaluate the pertinence of HF-PEF diagnosis and to compare HF-PEF and HF-REF patients with respect to outcomes. The analysis included 661 Polish patients hospitalized for HF, selected from the European Society of Cardiology (ESC)-HF Long-Term Registry. Patients with an EF of $\geq 50 \%$ were included in the HF-PEF group and patients with an EF of $<50 \%$ - in the HF-REF group. The primary end point was all-cause death at 1 year. The secondary end point was a composite of all-cause death and rehospitalization for HF at 1 year. HF-PEF was present in 187 patients (28\%). Of those 187 patients, mitral inflow pattern was echocardiographically assessed in 116 patients $(62 \%)$ and classified as restrictive/pseudonormal in 37 patients $(20 \%)$. Compared with HF-REF subjects, patients with HF-PEF were older, more often female, and had a higher prevalence of hypertension, atrial fibrillation and sleep apnea. Despite lower B-type natriuretic peptide concentrations and lower prevalence of moderate-to-severe mitral regurgitation in patients with HF-PEF, congestive symptoms at admission were as severe as in patients with HF-REF. There were no significant differences in in-hospital mortality between the HF groups. One-year mortality was high in both groups $(17 \%$ in HF-PEF vs $21 \%$ in HF-REF, $\mathrm{p}=0.22)$. There was a trend toward a lower frequency of the secondary end point in the HF-PEF group (32\% vs $40 \%, \mathrm{p}=0.07)$. In conclusion, in clinical practice, even easily obtainable echocardiographic indexes of diastolic dysfunction are relatively rarely acquired. One-year survival rate of patients with HF-PEF is not significantly better than that of patients with HF-REF. 
The prevalence of heart failure (HF) with preserved ejection fraction (HF-PEF) has increased over the last years, with a further increase to be anticipated due to aging of the population and a growing incidence of arterial hypertension, obesity, and type 2 diabetes. ${ }^{1-3}$ In clinical practice, adequate echocardiographic evaluation of diastolic function tends to be neglected, as it necessitates a comprehensive examination, incorporating all relevant 2-dimensional, pulsed-wave Doppler (PWD) and tissue Doppler imaging (TDI) data. ${ }^{4,5}$ Thus, HF-PEF becomes a diagnosis by exclusion, potentially leading to HF misdiagnosis in patients in whom the actual cause of dyspnea or diminished exercise capacity fails to be identified. Another problem in HF-PEF is the choice of optimal pharmacotherapy, as - so far - no treatment has been shown to improve survival in HF-PEF., ${ }^{3,6,8}$ The aim of the study was to estimate the prevalence of HF$\mathrm{PEF}$ in patients hospitalized for HF decompensation, to validate the pertinence of HF-PEF diagnosis in these patients, and to assess their clinical profile and outcomes in comparison to patients with HF with reduced EF (HF-REF).

\section{Methods}

The European Society of Cardiology (ESC) HF Long-Term Registry is an on-going, prospective, international, observational survey, with 211 cardiology centers from 21 European countries participating. ${ }^{9}$ The Registry includes both chronic HF patients presenting to ambulatory care clinics and patients admitted to hospital for new-onset or worsening HF. All patients with a diagnosis of HF who are aged $\geq 18$ years are eligible for enrollment. The survey was approved by local ethical review boards according to the regulations of each participating country. A signed, informed consent was obtained from each patient after providing him/her with detailed information on the Registry.

During phase I of the Registry, lasting from May 2011 to April 2013, patients were enrolled on 1 specific day of the week for 12 consecutive months in each of the participating centers. In phase II/III of the Registry (currently on-going), patients are enrolled during 5 consecutive days per trimester. Data on clinical characteristics, diagnostic tests performed, and implemented treatment are collected in the Registry. Electronic case report forms (eCRFs) enable to describe echocardiographically evaluated left ventricular (LV) diastolic function by (1) denominating whether LV filling pattern, assessed by PWD, is restrictive/pseudonormal or not (yes vs no); (2) entering the value of the early (E) to late (A) LV filling velocity ratio (E/A ratio); and (3) entering the value of wave $\mathrm{E}$ deceleration time. Information on the presence of LV hypertrophy (LVH) is given dichotomically (yes vs no). It is also possible to enter left atrial (LA) dimension (measured in parasternal long-axis view) and LA volume in the Registry's eCRF. All patients are followed for 12 months.

The current analysis included Polish patients hospitalized for HF, enrolled during phase I of the Registry. To discriminate between patients with HF-PEF and patients with HF-REF, the analysis included only those patients who had an echocardiographic examination (with EF assessment) performed during index hospitalization. Patients with an EF of $\geq 50 \%$ were included in the HF-PEF group, and patients with an $\mathrm{EF}$ of $<50 \%$ were included in the HF-REF group.

To verify the pertinence of HF diagnosis in patients with $\mathrm{EF} \geq 50 \%$, we assessed whether they met the echocardiographic criteria for HF-PEF according to the 2012 ESC HF guidelines, that is, the presence of LVH and/or LA enlargement (defined as LA dimension of $>40 \mathrm{~mm}$ and/or LA volume of $>34 \mathrm{ml} / \mathrm{m}^{2}$ ) and/or LV diastolic dysfunction (defined, for the sake of the current analysis, as restrictive/pseudonormal $\mathrm{LV}$ filling pattern and/or as E/A ratio of $\geq 2) .{ }^{6} \mathrm{We}$ also evaluated serum concentrations of B-type natriuretic peptide (BNP) and of N-terminal pro-BNP (NT-proBNP) in these patients, and, after 2012 ESC guidelines, adopted a threshold of $\geq 100 \mathrm{pg} / \mathrm{ml}$ for BNP levels and of $\geq 300 \mathrm{pg} / \mathrm{ml}$ for NT-proBNP as justifying HF suspicion in patients hospitalized for exacerbation of symptoms suggestive of $\mathrm{HF} .{ }^{6} \mathrm{We}$ applied ESC guidelines, as the Registry was conducted in the European population. 
The HF-PEF and HF-REF groups were compared with regard to clinical profile, initial presentation, diagnostic tests results, clinical course and management during index hospitalization, as well as inhospital and 1-year outcomes.

The primary end point was all-cause death at 1 year. The secondary end point was a composite of allcause death and hospital readmission for HF worsening at 1 year. We assessed the frequency of the primary and the secondary end points in both HF groups. In addition, we sought to determine predictors of the primary and the secondary end points separately for the HF-PEF and for the HF-REF group.

All statistical analyses were conducted using the SAS software, version 9.2 (SAS Institute Inc., Cary, NC). Normally distributed continuous variables were presented as mean $( \pm \mathrm{SD})$, whereas ordinal variables and nonnormally distributed continuous variables were presented as median (interquartile range). The HF-PEF and HF-REF groups were compared using the Fisher's exact test for categorical variables and the Mann-Whitney test for continuous and ordinal variables. Kaplan-Meier curves were plotted for the primary and the secondary end points in both groups. To identify the predictors of the primary and the secondary end points, Cox proportional hazards regression analyses were performed. All variables predictive of the primary or the secondary end points in univariate analyses were consequently included in multivariate models. All tests were 2 tailed. For all tests, a p value of $<0.05$ was deemed significant.

\section{Results}

The final analysis included 661 Polish in-hospital patients with echocardiography performed during index hospitalization: 187 patients (28\%) with EF of $\geq 50 \%$ (HF-PEF group) and 474 patients (72\%) with EF of $<50 \%$ (HF-REF group), as shown in Figure 1. In the studied cohort of 661 patients with HF, 229 subjects (35\%) had EF of $\geq 45 \%$, and 292 patients (44\%) had EF of $\geq 40 \%$.

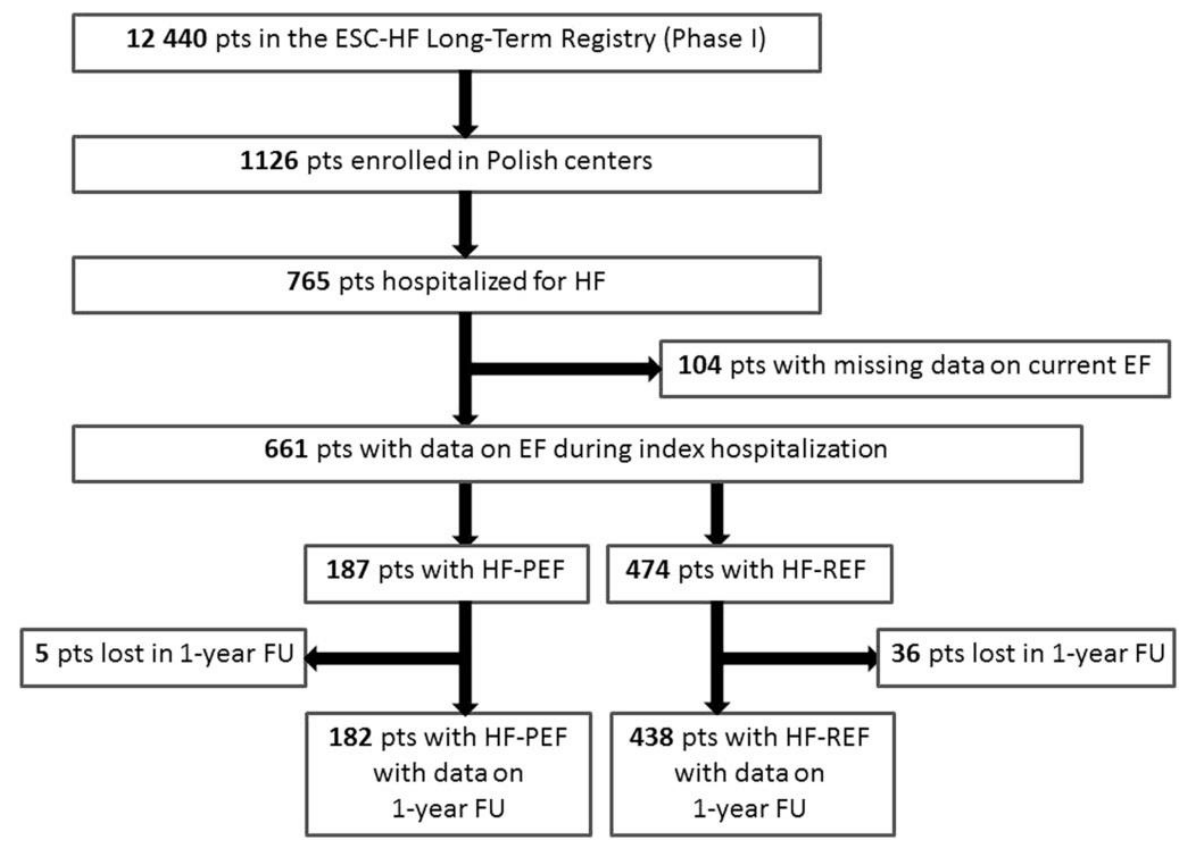

Figure 1. Flow chart of patient selection for the current analysis. FU = follow-up; pts = patients. 
Baseline characteristics, clinical course of index hospitalization, management and diagnostic tests performed during hospitalization, as well as in-hospital and 1-year outcomes of patients with HF-PEF and HF-REF are presented in Table 1, Table 2, Table 3.

Detailed echocardiographic and laboratory characteristics of patients with HF-PEF are presented in Table 2. Of 187 patients in the HF-PEF group, 144 patients (77\%) met the echocardiographic criteria for HF-PEF, as defined in the Methods section (i.e., the presence of LVH, LA dilation, restrictive/pseudonormal LV filling pattern, and/or E/A ratio of $\geq 2$ ). This was mostly due to the presence of LVH (assessed in 183 patients [98\%] and confirmed in 96 patients [51\% of the whole HF-PEF group]) and LA dilation (assessed in 137 patients [73\%] and confirmed in 94 patients [50\% of the whole HF-PEF group]). The PWD mitral inflow velocity pattern was assessed in $116(62 \%)$ of 187 patients in the HF$\mathrm{PEF}$ group, with exact values of E/A ratio given only in $52(28 \%)$ of 187 patients. Merely 37 patients ( $20 \%$ of the whole HF-PEF group) were classified as demonstrating a restrictive/pseudonormal LV filling pattern by the Registry's investigators. Deceleration time of the E wave was assessed only in 27 (14\%) of the 187 patients.

Serum concentrations of NT-proBNP were measured in $62(33 \%)$ of 187 patients with HF-PEF. Of those 62 patients, 57 patients $(92 \%)$ had an NT-proBNP level of $\geq 300 \mathrm{pg} / \mathrm{ml}$. Serum concentrations of BNP were evaluated in $33(18 \%)$ of 187 patients with HF-PEF, all of them had a BNP level of $\geq 100$ $\mathrm{pg} / \mathrm{ml}$. Of 187 patients from the HF-PEF group, 162 patients (87\%) either met the prespecified echocardiographic criteria for HF-PEF or had an NT-proBNP level of $\geq 300 \mathrm{pg} / \mathrm{ml}$ or a BNP level of $\geq 100$ $\mathrm{pg} / \mathrm{ml}$.

Of 620 patients with data on 1 -year follow-up, 122 patients $(20 \%)$ reached the primary end point: 30 patients in the HF-PEF group (including 3 patients who died during index hospitalization) and 92 patients in the HF-REF group (including 16 patients who died during index hospitalization), as presented in Table 3. The secondary end point was reached by 233 patients (38\%; Table 3). Kaplan-Meier curves for the primary and the secondary end points in both HF groups are plotted in Figures 2 and 3, respectively. Univariate analyses of predictors of the primary and the secondary end points in both groups are presented in the Supplementary Material (Tables S1 and S2). Multivariate analyses of predictors of the primary and the secondary end points for the HF-PEF and the HF-REF group are presented in Table 4. Due to the lack of complete data for some of the patients in the Registry, multivariate models included only those patients for whom all required parameters were available, that is, 177 patients from the HFPEF group and 420 patients from the HF-REF group for the primary end point analyses, and 176 patients from the HF-PEF group and 421 patients from the HF-REF group for the secondary end point analyses. 
Table 1. Baseline clinical characteristics and previous pharmacotherapy in patients with heart failure with preserved ejection fraction (HF-PEF) and in patients with heart failure with reduced ejection fraction (HF-REF)

\begin{tabular}{|c|c|c|c|}
\hline Variable & $\operatorname{HF}-\mathrm{PEF}(n=187)$ & HF-REF ( $n=474)$ & $P$ \\
\hline Age (years) & $77(69-84)$ & $67(58-76)$ & $<0.0001$ \\
\hline Women & $111(59 \%)$ & $110(23 \%)$ & $<0.0001$ \\
\hline $\operatorname{BMI}\left(\mathrm{kg} / \mathrm{m}^{2}\right)$ & $28.0(25.4-32.4) ; n=186$ & $27.6(24.9-30.8) ; n=472$ & 0.08 \\
\hline Last known EF before index hospitalization (\%) & $56(50-60) ; \mathrm{n}=102$ & $30(20-38) ; n=344$ & $<0.0001$ \\
\hline Last known EF (before index hospitalization) $\geq 50 \%$ & $83 / 102(81 \%)$ & $14 / 344(4 \%)$ & $<0.0001$ \\
\hline Primary described as HF-PEF & $20(11 \%)$ & $0(0 \%)$ & $<0.0001$ \\
\hline Primary ischemic etiology of $\mathrm{HF}$ & $62(33 \%)$ & $304(64 \%)$ & $<0.0001$ \\
\hline Dilated cardiomyopathy & $2(1 \%)$ & $96(20 \%)$ & $<0.0001$ \\
\hline Tachycardia-related cardiomyopathy & $6(3 \%)$ & $14(3 \%)$ & 0.81 \\
\hline Previous HF diagnosis & $148 / 186(80 \%)$ & $406 / 473(86 \%)$ & 0.06 \\
\hline Previous HF hospitalization & $78 / 186(42 \%)$ & $265 / 473(56 \%)$ & 0.001 \\
\hline Hypertension & $149(80 \%)$ & $325 / 472(69 \%)$ & 0.005 \\
\hline Coronary artery disease & $69(37 \%)$ & $293(62 \%)$ & $<0.0001$ \\
\hline Prior PCI or CABG & $31(17 \%)$ & $201 / 472(43 \%)$ & $<0.0001$ \\
\hline Previously implanted ICD & $3(2 \%)$ & $87(18 \%)$ & $<0.0001$ \\
\hline Previously implanted CRT & $1(0.5 \%)$ & $37(8 \%)$ & $<0.0001$ \\
\hline Pacemaker & $16(9 \%)$ & $23(5 \%)$ & 0.10 \\
\hline History of atrial fibrillation & $101(54 \%)$ & $204(43 \%)$ & 0.01 \\
\hline Prior stroke or TIA & $24(13 \%)$ & $43(9 \%)$ & 0.15 \\
\hline Peripheral artery disease & $32 / 186(17 \%)$ & $70 / 473(15 \%)$ & 0.47 \\
\hline Diabetes & $61(33 \%)$ & $170(36 \%)$ & 0.47 \\
\hline Chronic kidney disease & $52(28 \%)$ & $143(30 \%)$ & 0.57 \\
\hline Sleep apnea & $21 / 185(11 \%)$ & $15 / 466(3 \%)$ & $<0.0001$ \\
\hline Chronic obstructive pulmonary disease & $27(14 \%)$ & $70 / 473(15 \%)$ & 1.00 \\
\hline Current smoker & $8(4 \%)$ & $77(16 \%)$ & $<0.0001$ \\
\hline Current or former smoking & $69(37 \%)$ & $307(65 \%)$ & $<0.0001$ \\
\hline Loop diuretic & $100(54 \%)$ & $319(67 \%)$ & 0.001 \\
\hline Thiazide diuretic & $21(11 \%)$ & $23(5 \%)$ & 0.005 \\
\hline Aldosterone antagonist & $57(31 \%)$ & $250(53 \%)$ & $<0.0001$ \\
\hline ACE-I & $100(54 \%)$ & $317(67 \%)$ & 0.002 \\
\hline ARB & $24(13 \%)$ & $32(7 \%)$ & 0.02 \\
\hline Nitrates & $22(12 \%)$ & $54(11 \%)$ & 0.89 \\
\hline$\beta$-blocker & $133(71 \%)$ & $366(77 \%)$ & 0.11 \\
\hline Calcium channel blocker & $41(22 \%)$ & $55(12 \%)$ & 0.001 \\
\hline Ivabradine & $0(0 \%)$ & $3(0.6 \%)$ & 0.56 \\
\hline Digoxin & $26(14 \%)$ & $97(21 \%)$ & 0.06 \\
\hline Amiodarone & $11(6 \%)$ & $51(11 \%)$ & 0.06 \\
\hline Statin & $97(52 \%)$ & $271(57 \%)$ & 0.23 \\
\hline Antiplatelets & $90(48 \%)$ & $271(57 \%)$ & 0.04 \\
\hline Anticoagulants & $60(32 \%)$ & $156(33 \%)$ & 0.86 \\
\hline Insulin & $28(15 \%)$ & $67(14 \%)$ & 0.81 \\
\hline
\end{tabular}

Bold indicates $\mathrm{p}$ values of $<0.05$.

$\mathrm{ACE}-\mathrm{I}=$ angiotensin-converting enzyme inhibitor; $\mathrm{ARB}=$ angiotensin receptor blocker; $\mathrm{BMI}=$ body mass index; $\mathrm{CABG}=$ coronary artery bypass grafting; $\mathrm{CRT}=$ cardiac resynchronization therapy; $\mathrm{EF}=$ ejection fraction; $\mathrm{HF}=\mathrm{heart}$ failure; $\mathrm{ICD}=$ implantable cardioverter-defibrillator; $\mathrm{PCI}=$ percutaneous coronary intervention; TIA = transient ischemic attack. 
Table 2. Clinical and laboratory status at hospital admission, and echocardiographic findings during index hospitalization in patients with heart failure with preserved ejection fraction (HF-PEF) and in patients with heart failure with reduced ejection fraction (HFREF)

\begin{tabular}{|c|c|c|c|}
\hline & HF-PEF ( $n=187)$ & HF-REF $(n=474)$ & $P$ \\
\hline Cardiogenic shock & $2(1 \%)$ & $14(3 \%)$ & 0.26 \\
\hline NYHA class & $3(3-4)$ & $3(3-4) ; n=471$ & \\
\hline I & $0(0 \%)$ & $0(0 \%)$ & \\
\hline II & $41(22 \%)$ & $103 / 471(22 \%)$ & 0.93 \\
\hline III & $83(44 \%)$ & $212 / 471(45 \%)$ & \\
\hline IV & $63(34 \%)$ & $156 / 471(33 \%)$ & \\
\hline Pulmonary rales & $126(67 \%)$ & $298(63 \%)$ & 0.28 \\
\hline Pulmonary congestion/alveolar oedema on chest X-ray & $59 / 97(61 \%)$ & $136 / 222(61 \%)$ & 1.00 \\
\hline Right ventricular HF & $17(9 \%)$ & $14(3 \%)$ & 0.002 \\
\hline Peripheral oedema & $101(54 \%)$ & $239(50 \%)$ & 0.44 \\
\hline Systolic blood pressure (mmHg) & $135(120-160)$ & $120(110-140)$ & $<0.0001$ \\
\hline Diastolic blood pressure (mmHg) & $80(70-90)$ & $75(70-80) ; n=473$ & 0.0009 \\
\hline Heart rate (b.p.m.) & $80(70-100)$ & $80(70-100)$ & 0.72 \\
\hline Paced heart rhythm (ECG) & $11 / 186(6 \%)$ & $56 / 469(12 \%)$ & 0.02 \\
\hline $\mathrm{AF}(\mathrm{ECG})$ & $70 / 186(38 \%)$ & $111 / 469(24 \%)$ & $<0.0001$ \\
\hline $\mathrm{AF}$ as a cause of admission & $64(34 \%)$ & $139(29 \%)$ & 0.23 \\
\hline VF or VT as a cause of admission & $10(5 \%)$ & $55(12 \%)$ & 0.01 \\
\hline ACS as a cause of admission & $6(3 \%)$ & $71(15 \%)$ & $<0.0001$ \\
\hline Uncontrolled hypertension as a cause of admission & $44(24 \%)$ & $38(8 \%)$ & $<0.0001$ \\
\hline Renal dysfunction as a cause of admission & $20(11 \%)$ & $62(13 \%)$ & 0.44 \\
\hline NT-proBNP (pg/ml) & $1852(722-5286) ; n=62$ & $4085(1691-8675) ; n=203$ & 0.0001 \\
\hline $\mathrm{BNP}(\mathrm{pg} / \mathrm{ml})$ & $217(116-479) ; n=33$ & $656(249-1337) ; n=64$ & 0.0004 \\
\hline Serum sodium (mmol/1) & $140(137-142) ; n=185$ & $139(137-141) ; n=472$ & 0.005 \\
\hline Serum creatinine (mg/dl) & $1.02(0.84-1.27) ; \mathrm{n}=185$ & $1.14(0.91-1.43) ; n=472$ & 0.0003 \\
\hline Hemoglobin $(\mathrm{g} / \mathrm{dl})$ & $13.3(11.8-14.3) ; \mathrm{n}=185$ & $13.5(12.2-14.6) ; n=469$ & 0.03 \\
\hline \multicolumn{4}{|l|}{ Echocardiography } \\
\hline Ejection fraction $(\%)$ & $55(50-60)$ & $30(21-38)$ & $<0.0001$ \\
\hline LVEDD (mm) & $48(43-52) ; n=173$ & $60(54-70) ; n=444$ & $<0.0001$ \\
\hline Left ventricular hypertrophy & $96 / 183(53 \%)$ & $165 / 446(37 \%)$ & 0.0005 \\
\hline $\mathrm{E} / \mathrm{A} \geq 2$ & $2 / 52(4 \%)$ & $42 / 135(31 \%)$ & $<0.0001$ \\
\hline $\mathrm{E} / \mathrm{A}<1$ & $33 / 52(64 \%)$ & $64 / 135(47 \%)$ & 0.05 \\
\hline $\mathrm{E} / \mathrm{A}[1-2)$ & $17 / 52(33 \%)$ & $29 / 135(22 \%)$ & 0.13 \\
\hline Restrictive/pseudonormal pattern* & $37 / 116(32 \%)$ & $150 / 319(47 \%)$ & 0.006 \\
\hline Deceleration time $(\mathrm{ms})^{\dagger}$ & $203(140-290) ; n=27$ & $149(108-218) ; n=64$ & 0.04 \\
\hline LA dimension (mm) & $47(40-54) ; n=94$ & $48(43-52) ; n=229$ & 0.71 \\
\hline LA dimension $>40 \mathrm{~mm}$ & $70 / 94(75 \%)$ & $193 / 229(84 \%)$ & 0.71 \\
\hline LA volume $(\mathrm{ml})$ & $73(45-110) ; n=43$ & $55(45-90) ; n=66$ & 0.36 \\
\hline LA volume $>34 \mathrm{ml} / \mathrm{m}^{2}$ & $24 / 43(56 \%)$ & $26 / 65(40 \%)$ & 0.12 \\
\hline Aortic stenosis & $25 / 185(14 \%)$ & $31 / 466(7 \%)$ & 0.008 \\
\hline Aortic regurgitation ${ }^{\ddagger}$ & $13 / 186(7 \%)$ & $43 / 465(9 \%)$ & 0.44 \\
\hline Mitral regurgitation & $79 / 185(43 \%)$ & $272 / 466(58 \%)$ & $<0.0001$ \\
\hline Tricuspid regurgitation & $72 / 186(39 \%)$ & $199 / 466(43 \%)$ & 0.38 \\
\hline
\end{tabular}

Bold indicates $\mathrm{p}$ values of $<0.05$.

$\mathrm{ACS}=$ acute coronary syndrome; $\mathrm{AF}=$ atrial fibrillation; $\mathrm{BNP}=\mathrm{B}$-type natriuretic peptide; $\mathrm{E} / \mathrm{A}=$ early to late left ventricular filling velocity ratio; $\mathrm{ECG}=$ electrocardiogram; $\mathrm{LA}=$ left atrium; LVEDD = left ventricular end-diastolic diameter; NTproBNP = N-terminal proBNP; NYHA = New York Heart Association; VF = ventricular fibrillation; VT = ventricular tachycardia.

* Of mitral inflow.

$\dagger$ Of the E wave.

\$ Moderate or severe. 
Table 3. Management during index hospitalization, clinical status, laboratory findings and pharmacotherapy at discharge, as well as in-hospital and long-term outcomes of patients with heart failure with preserved ejection fraction (HF-PEF) and of patients with heart failure with reduced ejection fraction (HF-REF)

\begin{tabular}{|c|c|c|c|}
\hline Variable & $\operatorname{HF}-\mathrm{PEF}(n=187)$ & $\operatorname{HF}-\mathrm{REF}(n=474)$ & $P$ \\
\hline Inotropic support & $9(5 \%)$ & $82 / 472(17 \%)$ & $<0.0001$ \\
\hline Intravenous nitrates & $25(13 \%)$ & $56 / 471(12 \%)$ & 0.60 \\
\hline Intravenous diuretics & $106(57 \%)$ & $289 / 472(61 \%)$ & 0.29 \\
\hline Coronary angiography & $24(13 \%)$ & $160 / 471(34 \%)$ & $<0.0001$ \\
\hline $\mathrm{PCI} / \mathrm{CABG}$ & $10(5 \%)$ & $75 / 472(16 \%)$ & $<0.0001$ \\
\hline Holter-ECG & $67(36 \%)$ & $164 / 470(35 \%)$ & 0.86 \\
\hline Exercise test & $18 / 176(10 \%)$ & $63 / 463(14 \%)$ & 0.29 \\
\hline Heart rate (b.p.m.) * & $70(65-80)$ & $70(65-80)$ & 0.89 \\
\hline Systolic blood pressure $(\mathrm{mmHg})^{*}$ & $120(110-130)$ & $115(105-125)$ & $<0.0001$ \\
\hline NYHA class* & $2(2-3)$ & $2(2-3)$ & 0.002 \\
\hline I & $11(6 \%)$ & $16(4 \%)$ & \\
\hline II & $126(69 \%)$ & $268(59 \%)$ & \\
\hline III & $45(25 \%)$ & $165(36 \%)$ & \\
\hline IV & $2(1 \%)$ & $9(2 \%)$ & \\
\hline Serum creatinine $(\mathrm{mg} / \mathrm{dl})^{*}$ & $1.05(0.88-1.31) ; n=137$ & $1.12(0.94-1.41) ; n=354$ & 0.04 \\
\hline Loop diuretic* & $134(73 \%)$ & $390(85 \%)$ & 0.0004 \\
\hline Thiazide diuretic* & $16(9 \%)$ & $18(4 \%)$ & 0.02 \\
\hline Aldosterone antagonist* & $92(50 \%)$ & $345(75 \%)$ & $<0.0001$ \\
\hline ACE-I* & $114(62 \%)$ & $377(82 \%)$ & $<0.0001$ \\
\hline $\mathrm{ARB}^{*}$ & $30(16 \%)$ & $33(7 \%)$ & 0.001 \\
\hline Nitrates* & $16(9 \%)$ & $49(11 \%)$ & 0.56 \\
\hline$\beta$-blocker* & $151(82 \%)$ & $428(94 \%)$ & $<0.0001$ \\
\hline Bisoprolol* & $58(32 \%)$ & $143(31 \%)$ & 1.00 \\
\hline Carvedilol* $^{*}$ & $29(16 \%)$ & $193(42 \%)$ & $<0.0001$ \\
\hline Metoprolol* & $41(22 \%)$ & $55(12 \%)$ & 0.001 \\
\hline Nebivolol $^{*}$ & $14(8 \%)$ & $34(7 \%)$ & 1.00 \\
\hline Target $\beta$-blocker dose reached ${ }^{\dagger}$ & $10(5 \%)$ & $38(8 \%)$ & 0.25 \\
\hline Calcium channel blocker* & $51(28 \%)$ & $51(11 \%)$ & $<0.0001$ \\
\hline Ivabradine* & $0(0 \%)$ & $6(1 \%)$ & 0.19 \\
\hline Digoxin* & $33(18 \%)$ & $119(26 \%)$ & $\mathbf{0 . 0 3}$ \\
\hline Amiodarone* & $11(6 \%)$ & $69(15 \%)$ & 0.001 \\
\hline Statin* & $111(60 \%)$ & $332(73 \%)$ & 0.003 \\
\hline Antiplatelets* & $91(50 \%)$ & $304(66 \%)$ & 0.0001 \\
\hline Anticoagulants* & $90(49 \%)$ & $202(44 \%)$ & 0.29 \\
\hline Insulin* & $29(16 \%)$ & $76(17 \%)$ & 0.91 \\
\hline Hospitalization length (days) & $7(4-10)$ & $7(4-12)$ & 0.26 \\
\hline Death during hospitalization & $3(1.6 \%)$ & $16(3.4 \%)$ & 0.30 \\
\hline Death at 1 year & $30 / 182(17 \%)$ & $92 / 438(21 \%)$ & 0.22 \\
\hline Death or rehospitalization at 1 year & $58 / 182(32 \%)$ & $175 / 438(40 \%)$ & 0.07 \\
\hline
\end{tabular}

Bold indicates $\mathrm{p}$ values of $<0.05$.

ACE-I = angiotensin-converting enzyme inhibitor; $\mathrm{ARB}=$ angiotensin receptor blocker; $\mathrm{CABG}=$ coronary artery bypass grafting; $\mathrm{ECG}=$ electrocardiogram; NYHA = New York Heart Association; PCI = percutaneous coronary intervention.

* At discharge (in patients who survived to hospital discharge, i.e., in 184 patients with HF-PEF, and in 458 patients with HFREFs).

$\dagger$ That is: bisoprolol $\geq 10 \mathrm{mg}$ daily, carvedilol $\geq 50 \mathrm{mg}$ daily, metoprolol $\geq 200 \mathrm{mg}$ daily, or nebivolol $\geq 10 \mathrm{mg}$ daily. 


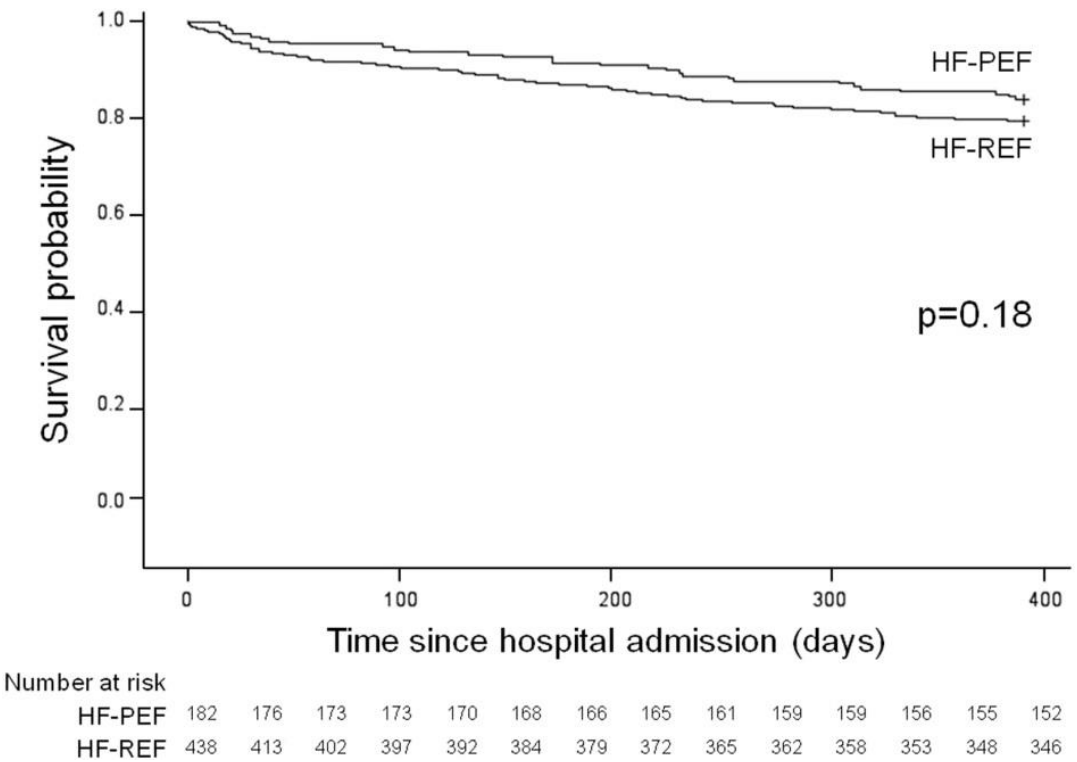

Figure 2. Kaplan-Meier curves for the primary end point in patients with HF-PEF and in patients with HF-REF.

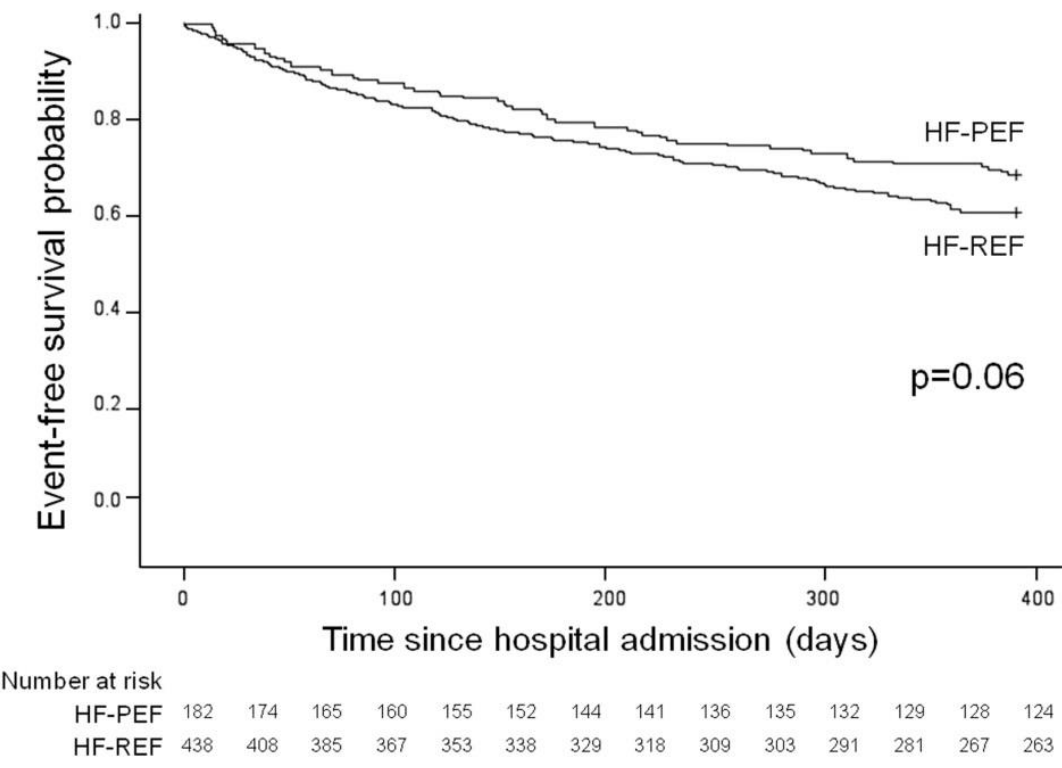

Figure 3. Kaplan-Meier curves for the secondary end point in patients with HF-PEF and in patients with HF-REF. 
Table 4. Multivariate analyses of predictors of the primary and the secondary end points in patients with heart failure with preserved ejection fraction and in patients with heart failure with reduced ejection fraction

\begin{tabular}{|c|c|c|c|c|}
\hline & \multicolumn{2}{|c|}{ Primary endpoint } & \multicolumn{2}{|c|}{ Secondary endpoint } \\
\hline & $\mathrm{HR}(95 \% \mathrm{CI})$ & $P$ & $\mathrm{HR}(95 \% \mathrm{CI})$ & $P$ \\
\hline \multicolumn{5}{|l|}{ Heart failure with preserved ejection fraction } \\
\hline Age (per 10 years) & $2.04(1.09-3.81)$ & 0.03 & $1.37(0.91-2.04)$ & 0.13 \\
\hline History of atrial fibrillation & - & - & $2.22(0.87-5.65)$ & 0.096 \\
\hline NYHA class* (per 1 class) & $2.91(1.31-6.47)$ & 0.009 & $2.35(1.32-4.18)$ & 0.004 \\
\hline Heart rate* (per 10 b.p.m.) & - & - & $0.96(0.83-1.13)$ & 0.65 \\
\hline Aortic stenosis ${ }^{\dagger}$ & $3.73(1.10-12.62)$ & 0.04 & $3.44(1.18-9.98)$ & 0.02 \\
\hline Tricuspid regurgitation $^{\dagger}$ & $2.49(0.91-6.78)$ & 0.07 & $1.13(0.46-2.75)$ & 0.80 \\
\hline Serum sodium* (per $1 \mathrm{mmol} / \mathrm{l})$ & - & - & $0.91(0.84-0.999)$ & 0.047 \\
\hline Serum creatinine* (per $1 \mathrm{mg} / \mathrm{dl}$ ) & $1.68(0.74-3.82)$ & 0.22 & $2.02(0.88-4.63)$ & 0.096 \\
\hline Hemoglobin* (per $1 \mathrm{~g} / \mathrm{dl})$ & $0.84(0.66-1.08)$ & 0.17 & $0.93(0.75-1.15)$ & 0.49 \\
\hline \multicolumn{5}{|l|}{ Heart failure with reduced ejection fraction } \\
\hline Age (per 10 years) & $1.45(1.15-1.83)$ & 0.002 & - & - \\
\hline Women & - & - & $1.95(1.17-3.25)$ & 0.01 \\
\hline Peripheral artery disease & $1.69(0.85-3.33)$ & 0.13 & $2.22(1.19-4.15)$ & 0.01 \\
\hline Chronic obstructive pulmonary disease & - & - & $1.37(0.76-2.47)$ & 0.30 \\
\hline NYHA class* (per 1 class) & $1.89(1.26-2.85)$ & 0.002 & $1.60(1.15-2.22)$ & 0.005 \\
\hline Systolic blood pressure* (per $10 \mathrm{mmHg}$ ) & $0.96(0.87-1.07)$ & 0.47 & $0.98(0.89-1.07)$ & 0.65 \\
\hline Heart rate ${ }^{*}$ (per 10 b.p.m.) & - & - & $1.06(0.98-1.15)$ & 0.17 \\
\hline Ejection fraction (per 5\%) & $0.85(0.73-0.99)$ & 0.04 & $0.87(0.77-0.98)$ & 0.02 \\
\hline Aortic regurgitation $^{\dagger}$ & $1.90(0.87-4.12)$ & 0.11 & $1.72(0.82-3.60)$ & 0.15 \\
\hline Mitral regurgitation $^{\dagger}$ & $1.19(0.67-2.11)$ & 0.56 & $1.18(0.73-1.88)$ & 0.50 \\
\hline Tricuspid regurgitation $^{\dagger}$ & $0.92(0.52-1.63)$ & 0.78 & $1.02(0.63-1.64)$ & 0.94 \\
\hline Serum sodium* (per $1 \mathrm{mmol} / \mathrm{l})$ & $0.92(0.86-0.97)$ & 0.004 & $0.99(0.94-1.04)$ & 0.64 \\
\hline Serum creatinine* (per 1 mg/dl) & $1.11(0.80-1.54)$ & 0.54 & - & - \\
\hline Hemoglobin* $($ per $1 \mathrm{~g} / \mathrm{dl})$ & $0.94(0.82-1.08)$ & 0.39 & - & - \\
\hline PCI/CABG during hospitalization & - & - & $0.61(0.30-1.23)$ & 0.17 \\
\hline ACE-I or ARB ${ }^{\ddagger}$ & - & - & $0.40(0.21-0.76)$ & 0.006 \\
\hline
\end{tabular}

Bold indicates $\mathrm{p}$ values of $<0.05$.

ACE-I = angiotensin-converting enzyme inhibitor; ARB = angiotensin receptor blocker; $\mathrm{CABG}=$ coronary artery bypass grafting; $\mathrm{CI}=$ confidence interval $\mathrm{HR}=$ hazard ratio; NYHA = New York Heart Association; $\mathrm{PCI}=$ percutaneous coronary intervention

* At hospital admission.

$\dagger$ Moderate or severe.

\$ At hospital discharge. 


\section{Discussion}

In the presented analysis, the prevalence of HF-PEF among hospitalized HF patients was $28 \%, 35 \%$, and $44 \%$, depending on the cut-off value for "preserved" $E F$ ( $\geq 50 \%, \geq 45 \%$, and $\geq 40 \%$, respectively). This is similar to HF-PEF prevalence observed in the whole population of hospitalized ESC-HF LongTerm Registry patients (31\% for "preserved" EF threshold of $>45 \%)$. ${ }^{9}$ Data from previously published studies demonstrate that the proportion of patients with HF-PEF among all patients with HF varies widely from $25 \%$ to $71 \%$, depending on the adopted threshold for "preserved" EF, as well as on the clinical setting and study type. ${ }^{1,2,3,10,11,12}$ In previous large, prospective registries, patients with preserved EF constituted approximately half of patients hospitalized for acute HF. ${ }^{13,14,15}$

The echocardiographic criteria for HF-PEF we adopted in the current analysis were fairly mild, that is, required the presence of only one of the abnormalities suggestive of LV diastolic dysfunction, including the presence of LA dilation, which is very unspecific for LV diastolic dysfunction and might be attributable to a number of other conditions, such as hypertension or atrial fibrillation (both highly prevalent in the population studied). ${ }^{4,5,16,17}$ Still, almost one quarter of the HF-PEF group in our study did not fulfill those mild echocardiographic criteria. Furthermore, the diagnosis of HF-PEF was actually confirmed by the presence of restrictive/pseudonormal mitral inflow pattern in merely $20 \%$ of patients. Thus, the remaining $80 \%$ of patients with $\mathrm{EF} \geq 50 \%$ and no convincing evidence for significant LV diastolic dysfunction might have been misdiagnosed with HF. Possibly, some of those patients were classified as HF-PEF based on the E/A ratio of $<1$, which may be indicative of impaired LV relaxation. ${ }^{45}$ However, it has been well established that in healthy persons aged $>60$ years, the E/A ratio decreases below 1 (together with a prolongation of the $\mathrm{E}$ wave deceleration time). ${ }^{4,5,18}$ Therefore, the diagnosis of HF-PEF based solely on the value of E/A ratio $<1$ in patients more than 60 years old is not justified (median age in the studied HF-PEF group was 77 years). According to the present guidelines, evaluation of LV diastolic function in patients with suspected HF-PEF should be largely based on the estimation of TDI-assessed early diastolic velocities of mitral annulus (e') and the E/e' ratio. ${ }^{4,5}$ Unfortunately, the eCRF of the ESC-HF Long-Term Registry did not allow entering TDI-derived measurements.

The clinical profile of patients with preserved EF in our analysis corresponds to the previously described characteristics of HF-PEF population, with a higher prevalence of hypertension, atrial fibrillation, obesity, and female gender, and patients being older compared with HF-REF population. $2,3,10,11,12,13,14,15,19,20$ Interestingly, although coronary artery disease (CAD) is a risk factor for the development of diastolic dysfunction, this ultimately progresses to systolic dysfunction in a vast number of patients with CAD; thus, the observed prevalence of CAD is higher in patients with HF-REF than in patients with HF-PEF.,12,13,14,21,22 Of note, many patients with HF-PEF may in fact exhibit impaired longitudinal and circumferential systolic LV function, despite preserved global EF. ${ }^{20,23}$ Importantly, HF-PEF is typically accompanied by a number of noncardiac co-morbidities (including diabetes, sleep apnea, chronic obstructive pulmonary disease, chronic kidney disease, and anemia), which - on one hand - might be involved in its development, and - on the other hand - deteriorate prognosis in $\mathrm{HF}^{2,10,12,21,24,25}$

Despite preserved EF, lower prevalence of moderate-to-severe mitral regurgitation and lower BNP/NT-proBNP concentrations on hospital admission, the severity of congestive symptoms in patients presenting with HF-PEF was similar to that observed in HF-REF. Consequently, the proportion of patients receiving intravenous nitrate or diuretic treatment was comparable in both HF groups. Nevertheless, patients with HF-REF more often required inotropic support.

In-hospital mortality rate of patients with HF-PEF was twice as low as of patients with HF-REF, but due to the low number of events, the difference did not reach statistical significance. Among patients who survived to hospital discharge, subjects with HF-PEF were characterized by a better functional status at discharge than those with HF-REF. However, no evident benefit in terms of 1-year mortality was demonstrated for the HF-PEF group. Previous studies have brought inconsistent results on survival in patients with HF-PEF compared with HF-REF, with similar prognosis in both HF groups demonstrated predominantly in epidemiological studies and registries, and with a $32 \%$ lower risk of death in HF-PEF in 
a meta-analysis including randomized clinical trials. ${ }^{2,3,10,11,12,13,14,15,21,26,27}$ According to previously published analyses, the most important risk factors for reduced survival in HF-PEF include advanced age, male gender, CAD, a greater noncardiac co-morbidity burden, renal impairment, hyponatremia, and both very high $\left(\geq 35 \mathrm{~kg} / \mathrm{m}^{2}\right)$ and normal-to-low $\left(<23.5 \mathrm{~kg} / \mathrm{m}^{2}\right)$ body mass index. ${ }^{14,26,28,29,30}$ To date, none of the medications routinely used in HF-REF has shown efficacy in improving prognosis of patients with HFPEF. ${ }^{3,6,7,8}$

The limitations of our study arise largely from the type of data (i.e., registry derived) we analyzed. First, there was a certain proportion of data missing for some of the patients. Second, the eCRF enabled investigators to enter only data predefined by the coordinators of the registry. In terms of evaluation of diastolic function, those were limited to PWD-assessed parameters of mitral inflow. Regretfully, no data on other important indexes of diastolic function were gathered in the registry. Therefore, definitive verification of the pertinence of HF-PEF diagnosis was not possible. Moreover, we were not able to assess how often each of those parameters is actually implemented in everyday clinical practice.

\section{Disclosures}

The authors have no conflicts of interest to disclose.

\section{Supplementary Data}

Supplementary data related with this article can be found, in the online version, at http://dx.doi.org/10.1016/j.amjcard.2016.05.046.

\section{References}

1. Steinberg BA, Zhao X, Heidenreich PA, Peterson ED, Bhatt DL, Cannon CP, Hernandez AF, Fonarow GC; Get With the Guidelines Scientific Advisory Committee and Investigators. Trends in patients hospitalized with heart failure and preserved left ventricular ejection fraction: prevalence, therapies, and outcomes. Circulation 2012;126: 65-75.

2. Owan TE, Hodge DO, Herges RM, Jacobsen SJ, Roger VL, Redfield MM. Trends in prevalence and outcome of heart failure with preserved ejection fraction. N Engl J Med 2006;355:251-259.

3. Shah SJ, Katz DH, Deo RC. Phenotypic spectrum of heart failure with preserved ejection fraction. Heart Fail Clin 2014;10:407-418.

4. Nagueh SF, Appleton CP, Gillebert TC, Marino PN, Oh JK, Smiseth OA, Waggoner AD, Flachskampf FA, Pellikka PA, Evangelisa A. Recommendations for the evaluation of left ventricular diastolic function by echocardiography. Eur J Echocardiogr 2009;10: 165-193.

5. Nagueh SF, Smiseth OA, Appleton CP, Byrd BF 3rd, Dokainish H, Edvardsen T, Flachskampf FA, Gillebert TC, Klein AL, Lancellotti P, Marino P, Oh JK, Popescu BA, Waggoner AD.

Recommendations for the evaluation of left ventricular diastolic function by echocardiography: an update from the American Society of Echocardiography and the European Association of Cardiovascular Imaging. J Am Soc Echocardiogr 2016;29:277-314.

6. McMurray JJ, Adamopoulos S, Anker SD, Auricchio A, Böhm M, Dickstein K, Falk V, Filippatos G, Fonseca C, Gomez-Sanchez MA, Jaarsma T, Køber L, Lip GY, Maggioni AP, Parkhomenko A, Pieske BM, Popescu BA, Rønnevik PK, Rutten FH, Schwitter J, Seferovic P, Stepinska J, Trindade PT, Voors AA, Zannad F, Zeiher A; ESC Committee for Practice Guidelines. ESC guidelines for the diagnosis and treatment of acute and chronic heart failure 2012. Eur Heart J 2012;33:1787-1847.

7. Yancy CW, Jessup M, Bozkurt B, Butler J, Casey DE Jr, Drazner MH, Fonarow GC, Geraci SA, Horwich T, Januzzi JL, Johnson MR, Kasper EK, Levy WC, Masoudi FA, McBride PE, McMurray JJ, Mitchell JE, Peterson PN, Riegel B, Sam F, Stevenson LW, Tang WH, Tsai EJ, Wilkoff BL; American College of Cardiology Foundation/ American Heart Association Task Force on Practice Guidelines. 2013 ACCF/AHA guideline for the management of heart failure: a report of the American College of Cardiology Foundation/American Heart Association task force on practice guidelines. Circulation 2013;128: e240-e327. 
8. Massie BM, Carson PE, McMurray JJ, Komajda M, McKelvie R, Zile MR, Anderson S, Donovan M, Iverson E, Staiger C, Ptaszynska A; I-PRESERVE Investigators. Irbesartan in patients with heart failure and preserved ejection fraction. N Engl J Med 2008;359:2456-2467.

9. Maggioni AP, Anker SD, Dahlström U, Filippatos G, Ponikowski P, Zannad F, Amir O, Chioncel O, Leiro MC, Drozdz J, Erglis A, Fazlibegovic E, Fonseca C, Fruhwald F, Gatzov P, Goncalvesova E, Hassanein M, Hradec J, Kavoliuniene A, Lainscak M, Logeart D, Merkely B, Metra M, Persson H, Seferovic P, Temizhan A, Tousoulis D, Tavazzi L; Heart Failure Association of the ESC. Are hospitalized or ambulatory patients with heart failure treated in accordance with European Society of Cardiology guidelines? Evidence from 12,440 patients of the ESC Heart Failure Long-Term Registry. Eur J Heart Fail 2013;15:1173-1184.

10. Quiroz R, Doros G, Shaw P, Liang CS, Gauthier DF, Sam F. Comparison of characteristics and outcomes of patients with heart failure preserved ejection fraction versus reduced left ventricular ejection fraction in an urban cohort. Am J Cardiol 2014;113:691-696.

11. Bhatia RS, Tu JV, Lee DS, Austin PC, Fang J, Haouzi A, Gong Y, Liu PP. Outcome of heart failure with preserved ejection fraction in a population-based study. N Engl J Med 2006;355:260-269.

12. Tsuchihashi-Makaya M, Hamaguchi S, Kinugawa S, Yokota T, Goto D, Yokoshiki H, Kato N, Takeshita A, Tsutsui H; JCARE-CARD Investigators. Characteristics and outcomes of hospitalized patients with heart failure and reduced vs preserved ejection fraction. Report from the Japanese Cardiac Registry of Heart Failure in Cardiology (JCARE-CARD). Circ J 2009;73:1893-1900.

13. Fonarow GC, Stough WG, Abraham WT, Albert NM, Gheorghiade M, Greenberg BH, O ' Connor CM, Sun JL, Yancy CW, Young JB. Characteristics, treatments, and outcomes of patients with preserved systolic function hospitalized for heart failure: a report from the OPTIMIZE-HF registry. J Am Coll Cardiol 2007;50:768-777.

14. Yancy CW, Lopatin M, Stevenson LW, De Marco T, Fonarow GC. Clinical presentation, management, and in-hospital outcomes of patients admitted with acute decompensated heart failure with preserved systolic function: a report from the Acute Decompensated Heart Failure National Registry (ADHERE) database. J Am Coll Cardiol 2006;47: 76-84.

15. Lenzen MJ, Scholte op Reimer WJ, Boersma E, Vantrimpont PJ, Follath F, Swedberg K, Cleland J, Komajda M. Differences between patients with a preserved and a depressed left ventricular function: a report from the EuroHeart Failure Survey. Eur Heart J 2004;25: 1214-1220.

16. Hammoudi N, Charbonnier M, Levy P, Djebbar M, Stankovic Stojanovic K, Ederhy S, Girot R, Cohen A, Isnard R, Lionnet F. Left atrial volume is not an index of left ventricular diastolic dysfunction in patients with sickle cell anaemia. Arch Cardiovasc Dis 2015;108:156-162.

17. Altekin RE, Yanikoglu A, Karakas MS, Ozel D, Yilmaz H, Demir I. Evaluation of left atrial function using two-dimensional speckle tracking echocardiography in end-stage renal disease patients with preserved left ventricular ejection fraction. Kardiol Pol 2013;71: 341-351.

18. Klein AL, Burstow DJ, Tajik AJ, Zachariah PK, Bailey KR, Seward JB. Effects of age on left ventricular dimensions and filling dynamics in 117 normal persons. Mayo Clin Proc 1994;69:212-224.

19. Ozieranski K, Kaplon-Cieslicka A, Peller M, Tyminska A, Balsam P, Galas M, Marchel M, CrespoLeiro M, Maggioni AP, Drozdz J, Opolski G. Clinical characteristics and predictors of one-year outcome of heart failure patients with atrial fi brillation compared to heart failure patients in sinus rhythm. Kardiol Pol 2016;74:251-261.

20. Iwano H, Little WC. Heart failure: what does ejection fraction have to do with it? J Cardiol 2013;62:1-3.

21. Lam CS, Donal E, Kraigher-Krainer E, Vasan RS. Epidemiology and clinical course of heart failure with preserved ejection fraction. Eur J Heart Fail 2011;13:18-28.

22. Wan SH, Vogel MW, Chen HH. Pre-clinical diastolic dysfunction. J Am Coll Cardiol 2014;63:407-416.

23. Kraigher-Krainer E, Shah AM, Gupta DK, Santos A, Claggett B, Pieske B, Zile MR, Voors AA, Lefkowitz MP, Packer M, McMurray JJ, Solomon SD; PARAMOUNT Investigators. Impaired systolic function by strain imaging in heart failure with preserved ejection fraction. $J$ Am Coll Cardiol 2014;63:447-456.

24. Mentz RJ, Kelly JP, von Lueder TG, Voors AA, Lam CS, Cowie MR, Kjeldsen K, Jankowska EA, Atar D, Butler J, Fiuzat M, Zannad F, Pitt B, O ' Connor CM. Noncardiac comorbidities in heart failure with reduced versus preserved ejection fraction. J Am Coll Cardiol 2014;64: 2281-2293.

25. Desai A, Fang JC. Heart failure with preserved ejection fraction: hypertension, diabetes, obesity/sleep apnea, and hypertrophic and infiltrative cardiomyopathy. Heart Fail Clin 2008;4:87-97.

26. Chan MM, Lam CS. How do patients with heart failure with preserved ejection fraction die? Eur J Heart Fail 2013;15:604-613.

27. Meta-analysis Global Group in Chronic Heart Failure (MAGGIC). The survival of patients with heart failure with preserved or reduced left ventricular ejection fraction: an individual patient data metaanalysis. Eur Heart J 2012;33:1750-1757. 
28. Alla F, Al-Hindi AY, Lee CR, Schwartz TA, Patterson JH, Adams KF Jr. Relation of sex to morbidity and mortality in patients with heart failure and reduced or preserved left ventricular ejection fraction. Am Heart J 2007;153:1074-1080.

29. Haass M, Kitzman DW, Anand IS, Miller A, Zile MR, Massie BM, Carson PE. Body mass index and adverse cardiovascular outcomes in heart failure patients with preserved ejection fraction: results from the Irbesartan in Heart Failure with Preserved Ejection Fraction (I-PRE- SERVE) trial. Circ Heart Fail 2011;4:324-331.

30. Bavishi C, Ather S, Bambhroliya A, Jneid H, Virani SS, Bozkurt B, Deswal A. Prognostic significance of hyponatremia among ambulatory patients with heart failure and preserved and reduced ejection fractions. Am J Cardiol 2014;113:1834-1838 . 